\title{
Aspectos bioéticos del aborto en Chile (2)
}

Un primer aspecto a considerar es lo bioético de nuestra Constitución respecto a la vida y la persona humana. El Capítulo III de la Constitución de Chile, trata De los Derechos y Deberes constitucionales (1). Dice el Artículo 19: La constitución asegura a todas las personas: $1^{\circ}$. El derecho a la vida y a la integridad física y psíquica de la persona. La ley protege la vida del que está por nacer.

En muchas constituciones la vida biológica del embrión pre-implantacional se transforma en sujeto de protección legal desde la implantación o nidación en el endometrio. Otras legislaciones consideran al embrión como persona humana a partir de la generación de células madres del sistema nervioso, o de la placa neural (2).

El citado texto redactado y contextualizado, ha interpretado al embrión pre-implantacional como persona humana, por organismos académicos expertos, desde la concepción o fusión de los pronúcleos óvulo-espermatozoide (3). Esta interpretación coincide con el criterio del magisterio de la Iglesia Católica, pero no se condice con sus propias interpretaciones teológicas del comienzo del ser humano como persona (4).

La Academia Pontificia para la Vida dice: “¿De todo ello se puede concluir que el embrión humano en la fase de la pre-implantación ya es realmente una persona? Es obvio que, tratándose de una interpretación filosófica, la respuesta a esta pregunta no es de «fe definida» y permanece abierta, en cualquier caso, a ulteriores consideraciones" (5). En general todas las religiones están abiertas a los derechos humanos y civiles de la mujer (6).

La pregunta es: ¿Es bioético redactar una Constitución en contextos que se preste a interpretaciones ambiguas? ¿Se considera aceptable por la bioética que una determinada filosofía imponga principios básicos como verdades absolutas a toda una población que ni siquiera profesa esa filosofía o creencia? ¿Es bioético que un artilugio de contexto suprima el ejercicio de derechos humanos fundamentales relacionados con la reproducción humana?
Un segundo aspecto se refiere a lo declarado por el Colegio Médico de Chile y lo normado por el Ministerio de Salud, acerca de la conducta bioética de los profesionales de la salud. El Código de Ética del Colegio Médico dice en el Título II: Deberes Generales del Médico, artículo 8: Respeto de la vida humana desde su inicio y hasta su término constituye el fundamento básico del ejercicio profesional médico. Toda intervención médica realizada durante los nueve meses de gestación, deberá velar siempre por el mejor interés de la madre y del hijo. En este texto no se determinan límites de inicio, pero se dan prioridades de la madre y del hijo.

El secreto profesional y la confidencialidad se describe en los artículos 29 al 38 y es inherente a la profesión. Solo puede ser develado a solicitud del paciente o con su autorización en documento firmado, el secreto incluye toda la información relativa al paciente, se debe cautelar las medidas para mantener la confidencialidad, incluyendo los registros de información y publicaciones científicas. El profesional no debe formar parte de bancos de datos o convenios donde se den datos confidenciales de pacientes. En el Artículo 38 se encuentran las excepciones donde se libera al médico para entregar información que son:

a) Enfermedades de declaración obligatoria, b) Lo ordenen los Tribunales de Justicia, c) Certificación de nacimientos y muertes, d) Evitar perjuicios graves al paciente o terceros y e) Datos para la defensa en juicios de mala práctica entablados por el paciente (7).

El Ministerio de Salud ha respaldado la confidencialidad en los casos de mujeres que requieran atención médica por complicaciones de salud asociadas a la realización de abortos. El Ordinario A15 N ${ }^{\circ} 1675$ del 24 de abril de 2009, basado en el Artículo $15^{\circ}$ de la Convención contra la Tortura y Otros Tratos o Penas Crueles, Inhumanos o Degradantes, establece: "Ninguna declaración que demuestre ha sido hecha como resultado de tortura pueda ser invocada como prueba en ningún procedimiento". En consecuencia y pese al tipo penal 
que describe como ilícito al aborto, los médicos y personal de salud no deben extraer confesiones sobre dicha conducta a las mujeres que requieran atención médica, como resultado de dicho ilícito, cuando con ello se vulnera el secreto profesional derivado de la relación de confidencialidad médicopaciente. Dicha relación está especialmente protegida por la ley, cuando ésta establece la facultad de abstenerse de declarar en procesos penales por razones de secreto, tales como en los casos de médicos (Artículo 303 Código Procesal Penal). La ley también protege la relación médico-paciente y la convierte en un imperativo legal, cuando establece la obligación de guardar secreto en materias que por su naturaleza tengan dicho carácter (Artículo 61, letra h del Estatuto Administrativo).

Todo lo anterior es coincidente con las políticas sanitarias del Gobierno de Chile, que ha suscrito el Programa de Acción de la Conferencia Internacional sobre Población y el Desarrollo en 1994, el cual establece que: "en todos los casos, las mujeres deberán tener acceso a servicios de calidad para tratar las complicaciones derivadas de abortos. Se deberían ofrecer con prontitud servicios de planificación de la familia, educación y asesoramiento post-aborto que ayuden también a evitar la repetición de los abortos" (8). Se incluyen los textos, puesto que se han realizado denuncias por parte de Directores de Maternidades, personal de Turno y directores de Servicio, que han terminado en encarcelamiento de mujeres aun no mayores de 20 años, incluso menores de 16 años. A pesar de las indicaciones del Ordinario 1675 a los Directores Regionales de Salud y Directores de Hospitales, se siguen repitiendo los casos de denuncias de mujeres usuarias de Misoprostol que consultan por temor a tener complicaciones como un flujo rojo abundante.

El registro de este fármaco adquirido clandestinamente no tiene la evidencia de su consumo y sólo ha bastado la información del profesional denunciante para que la mujer tenga prisión preventiva que puede ser a veces por 9 días o más. Esto esta absolutamente reñido con la bioética y no tiene justificación ninguna. Es una visión sesgada, particular y abuso de poder del denunciante. Es una acción desigual, vejatoria, estigmatizadora y con consecuencia de pérdida del empleo de la paciente $(9,10)$.

Un tercer aspecto es el discurso del Código de Derecho Sanitario y lo que muestra la información del Departamento de Estadísticas e Informática del Ministerio de Salud (DEIS). El Artículo 119 del Código de Derecho Sanitario dice: "no podrá ejecutarse ninguna acción cuyo fin sea provocar un aborto". No se conoce reglamento de esta ley. Chile es uno de los 5 países del mundo con una ley tan drástica.

Los egresos hospitalarios por aborto entre el 2001 y 2010 , reportados por el DEIS, según la CIE
10, alcanzaron un promedio anual de 33.451. Un $49,25 \%$ fueron por: embarazo ectópico (O00), mola hidatiforme (001), otros productos anormales de la concepción y mola no hidatiforme (002), las complicaciones de estas causas (O08) e intento fallido de aborto (O07). El 50\% son por indicaciones de salud no contempladas en el Código de Derecho Sanitario (11).

Preguntado el Ministerio de Salud, en la Cámara de Diputados acerca de la necesidad para revisar la legislación por esta incongruencia, la respuesta fue: "En Chile no existen casos en los que se haga correr un riesgo imprudente para la salud de la madre o que la madre se ponga en riesgo vital con el afán de continuar con el embarazo. Y cada vez que los equipos médicos se enfrentan a esta disyuntiva tratan a la madre aún si eso tiene como consecuencia indeseable el término del embarazo". La conclusión fue que no era necesario revisar la ley.

Esto es una bioética reñida con la verdad. Se vulnera el principio de la justicia, pues queda a la decisión del profesional, cómo y cuándo ejecuta las acciones de una buena práctica como ha ocurrido con el embarazo ectópico, cuya intervención se ha postergado hasta que la indicación fuese por la complicación de ruptura de la trompa de Falopio, con riesgos innecesarios y afectando la fertilidad futura de la paciente, o postergando un legrado uterino hasta no tener una hemorragia de un embarazo molar ya diagnosticado, o postergando la interrupción de un embarazo menor de 22 semanas por una sepsis materna grave, o por una crisis hipertensiva severa sin respuesta al tratamiento y signos de inminente ruptura hepática. Son casos de baja frecuencia pero de mucha gravedad, como hay muchos otros. Se afecta el principio de la No Maleficencia y de la Beneficencia.

Por cierto que quedan fuera todas las posibilidades de interrumpir un embarazo a solicitud de la madre, en el cual la vida intrauterina del embrión o del feto es incompatible, o con la certeza que su vida extrauterina al término será de minutos o semanas, -dada la gravedad e imposibilidad de reparación de las malformaciones- con todo el impacto que ello significa. Aquí se afecta el principio de Respeto por la Persona agregando un sufrimiento y una crueldad innecesaria.

Es muy evidente que otras consideraciones no serán jamás de resolución de profesionales individuales, pues al no haber legislación tampoco hay un sistema organizado para resolver temas de muy alta complejidad, como son los ya descritos, y esto es una grave falta a todos los principios conocidos de la bioética en el orden de la Salud Pública de una Nación.

En este contexto y forma de enfocar el aborto, será prácticamente imposible legislar en el complejo 
problema del aborto en casos de violación o incesto. Esto involucra a una serie de instituciones y profesionales. La ejecución de la interrupción, si es necesaria, será de responsabilidad de un especialista calificado, pero la solución del problema no termina con el aborto. El impacto es psico-social individual y familiar, y por mucho tiempo de apoyo y seguimiento. Recientemente, los medios informativos han dado cuenta de una adolescente menor abusada sexualmente por un adulto, pareja de su madre biológica. Aparentemente era un abuso sexual crónico. Al no tener una legislación, se han pasado a llevar todos los principios de la bioética y todas las buenas prácticas basadas en las evidencias. Una sociedad que esconde estos problemas no tiene una conducta bioética adecuada.

Esta forma de enfocar un tema tan importante que afecta diariamente a muchas mujeres y familias necesita de legislación y dar las oportunidades de elección a la mujer abusada. La bioética en estos casos respeta las decisiones de las afectadas, pero las oportunidades las da la sociedad que asume con bioética las propuestas integrales de solución, y no se limita sólo a la judicialización de lo relacionado con la salud sexual y reproductiva.

El cuarto aspecto es analizar la posición bioética de la FIGO en algunos temas atingentes al aborto, pues la Sociedad Chilena de Obstetricia y Ginecología (SOCHOG) está afiliada como sociedad científica y con responsabilidades crecientes en ella, en estos últimos 30 años (12).

La reproducción natural humana es un proceso que comprende la producción de gametos masculinos y femeninos y su unión durante la fertilización. El embarazo es la parte del proceso que comienza con la implantación del "conceptus" en el seno de una mujer, y que termina con el nacimiento de un bebé o con un aborto.

Respecto a los aspectos éticos en el manejo de anomalías congénitas, son severas las que pueden resultar en muerte o una discapacidad severa. No hay una definición médica del umbral de severidad de la enfermedad o anomalía fetal, ni tampoco existe una definición de vida "normal" para un neonato. Una mujer tiene el derecho a discutir el acceso a la terminación del embarazo, en caso que sea permitido en su país. La decisión de continuar o terminar el embarazo debe ser una decisión individual y que recae en la mujer.

Ninguna mujer, más allá de la práctica del cribado ultrasónico rutinario, debe someterse al proceso de diagnóstico prenatal sin estar plenamente informada de sus objetivos, la eventual terminación del embarazo, y del riesgo potencial de aborto involuntario. Si después de un diagnóstico prenatal los padres optan por continuar el embarazo, se debe proporcionar la atención adecuada al recién nacido severamente enfermo o malformado.

Profesor Dr. Ramiro Molina Cartes.
Declaración de conflictos de interés: El autor de esta editorial es un creyente no afiliado a ninguna religión, partido político u organización filosófica o cultural confesional. Es un asociado libre a la Escuela de Salud Pública, al Departamento de Obstetricia y Ginecología de la Universidad de Chile y a la SOCHOG y otras Sociedades Científicas.

\section{REFERENCIAS}

1. Constitución Política de la República de Chile. 17 septiembre de 2005. Disponible en: http://www.leychile.cl/ Navegar?idNorma=242302. Acceso: 10 de agosto de 2013.

2. UNSW Embriology. Disponible en: http://php.med. unsw.edu.au/embryology/index.php?title=Neural_ System_Development. Acceso: 10 de agosto de 2013.

3. Aborto Terapéutico. Consideraciones médicas, éticas, jurídicas y del magisterio de la Iglesia Católica. Facultad de Medicina. Centro de Bioética. Departamento de Obstetricia y Ginecología. Centro de Estudios Avanzados. Pontificia Universidad Católica de Chile. pp 23-24. Producción Gráfica Víctor Donaire, 2002.

4. El embrión humano en la fase de la preimplantación. Aspectos científicos y consideraciones bioéticas. Ciudad del Vaticano, 8 de junio de 2006. Disponible en: http://www.medicoscatolicos.org.ar/documents/ vol_embr_spa.pdf. Acceso: 10 de agosto de 2013.

5. El embrión humano en la fase de la preimplantación. Pontificia Academia Pro Vita XII Asamblea. Congreso Internacional. Declaración Final. 26 de marzo de 2006. Disponible en: http://www.noticiasglobales.org/ documentoDetalle.asp?numero=57. Acceso el 10 de agosto de 2013.

6. Capitulo 8. Valores religiosos: pp 107-133 En: El drama del aborto. Aníbal Faúndez, José Barzelatto. Editores del Grupo TM s.a. Bogotá, Colombia. 2005.

7. Nuevo Código de Ética Colegio Médico de Chile A.G. Ed. Atenas Limitada. 2004.

8. Ministerio de Salud de Chile. Ordinario 1675, 24 de abril de 2009.

9. Lidia Casas. Mujeres procesadas por aborto. LOM ediciones. Santiago, Chile. 1996.

10. Encarceladas. Leyes contra el aborto en Chile. Un análisis de los derechos humanos. María Isabel Matamala Vivaldi. Printed in Canada. 1998.

11. Molina R, Molina T. Perfil de los egresos hospitalarios por abortos. 2001-2010. Información DEIS. Ministerio de Salud de Chile. En publicación.

12. FIGO. Ethical Issues in Obstetrics and Gynecology. By the FIGO Committee for the Study of Ethical Aspects of Human Reproduction and Women's Health. London, October 2009. Disponible en: http://www.figo. org/files/figo-corp/Ethical\%20lssues\%20-\%20English. pdf. Acceso 10 de agosto de 2013. 